\title{
PROGNOSIS OF 'OBSERVATION HIP' IN CHILDREN
}

\author{
BY \\ CYRIL P. MONTY* \\ From the Orthopaedic Unit, Fulham Hospital
}

(RECEIVED FOR PUBLICATION MAY 3, 1962)

The child with a painful hip of sudden onset is frequently seen in both hospital and private practice. In many cases, after clinical examination and investigation, the condition causing the pain is diagnosed and appropriate treatment commenced. There still remains, however, a large proportion of cases in which, despite marked clinical signs, no causative condition can be confidently diagnosed. The patient recovers spontaneously with no treatment other than a variable period of bed rest.

This well-known clinical syndrome has been given many names in the past half-century, the wide range emphasizing the lack of knowledge as to its causation. The author prefers the term 'Observation Hip', first used by Fairbank (1926), since the diagnosis is essentially one of exclusion. This does not prejudge the aetiology or pathology.

The purpose of this paper is not to discuss aetiology or pathology but to show that this condition is essentially benign and does not give rise to any form of hip disease in later life.

\section{Historical Survey}

The first series of case reports was by Bradford (1912) who described 25 cases of what he termed 'transient arthritis'. In discussing non-tuberculous coxitis in children, Todd (1925) called it 'transient coxitis'. Belmonte (1931) summed up the condition by stating: 'It is wonderful how functional disturbance completely disappears in several days and after 10-12 days all complaints depart.' In differentiating it from tuberculous coxitis, he suggested a number of names-'coxitis serosa seu simplex', 'fugitive or ephemeral coxitis', 'coxitis fugax', or simply 'coxitis of unknown cause'. The largest series of cases was that published by Miller (1931) who described 77 cases of 'acute transient epiphysitis'. Butler (1933) favoured the original term of 'transitory arthritis'. In America several authors detailed a series of cases of 'transitory synovitis', this diagnosis being preferred by Finder (1936), Rauch (1940), Edwards (1952), Donaldson (1955),

\footnotetext{
* Present address: Dulwich Hospital, London.
}

Fox and Griffin (1956) and Rosenberg and Smith (1956). This was also the diagnosis given in two series published on the Continent by Sterner (1954) and Gianelli and Possenti (1954). In presenting 46 cases, Caravias (1956) used the term 'irritable hip', but he pointed out that the term was first used by Hugh Owen Thomas. Other names given to this condition are 'non-specific synovitis' (Jones and Ramsey, 1956) and 'toxic synovitis' (Wilson, 1955).

The opinion of the authors of these series as to the aetiology of the condition is evenly divided between traumatic and infective theories, toxicity and allergy also being mentioned. In the series of Miller (1931) some of the films showed small abscesses and bone absorption near the epiphyseal line. Drey (1953) described exaggerated shadows of the obturator internus, ilio-psoas and gluteus minimus due to swelling, and this finding was confirmed in some of the cases in the series of Hermel and Sklaroff (1954) and Donaldson (1955).

\section{Present Series}

This comprises 33 cases of 'observation hip' out of a total of 98 children with pain in the hip who were admitted to Fulham Hospital in the decade 1951-1961. After a full history had been taken and a clinical examination had been performed, the child was put to bed and his temperature recorded every four hours. The following investigations were carried out as a routine. White cell count (W.B.C.) and differential; erythrocyte sedimentation reaction (E.S.R.); throat swab; and radiograph of both hips.

In this way a diagnosis was arrived at wherever possible. Table 1 shows the differential diagnoses of the total number of 98 cases. Osteomyelitis of the upper femur was found in 21 children; 12 others complained of a sore throat, pathogenic organisms being found in the throat swab taken from 11 of the patients. A further 12 had a history of trauma, often of a trivial nature, in the few days before the onset of hip pain. Perthes' disease was diagnosed 
TABLE 1

DIFFERENTIAL DIAGNOSIS IN 98 CASES OF CHILDREN WITH PAINFUL HIP

\begin{tabular}{|c|c|c|c|c|c|}
\hline \multicolumn{5}{|c|}{ Diagnosis } & No. of Cases \\
\hline $\begin{array}{l}\text { Osteomyelitis of upper } \\
\text { Sore throat } \\
\text { Traumatic ... } \\
\text { Perthes' disease ... } \\
\text { Septic arthritis of hip } \\
\text { Previous osteomyelitis } \\
\text { Slipped epiphysis } \\
\text { Still's disease ... } \\
\text { Congenital dislocation } \\
\text { Otitis media ... } \\
\text { Boils of the leg ... } \\
\text { Paronychia of a finger } \\
\text { Urinary infection }\end{array}$ & $\begin{array}{l}\text { femur } \\
\ldots \\
\ldots \\
\ldots \\
\ldots \\
\text {. } \\
\text { of hip } \\
\text {. } \\
\text {. } \\
\text {. }\end{array}$ & $\begin{array}{l}\ldots \\
\cdots \\
\cdots \\
\cdots \\
\cdots \\
\cdots \\
\cdots \\
\cdots \\
\cdots \\
\cdots\end{array}$ & $\begin{array}{l}\cdots \\
\cdots \\
\cdots \\
\cdots \\
\cdots \\
\cdots \\
\cdots \\
\cdots \\
\cdots \\
\cdots\end{array}$ & $\begin{array}{l}\cdots \\
\cdots \\
\cdots \\
\cdots \\
\cdots \\
\cdots \\
\cdots \\
\cdots \\
\cdots \\
\cdots\end{array}$ & $\begin{array}{r}21 \\
12 \\
12 \\
7 \\
4 \\
2 \\
1 \\
1 \\
1 \\
1 \\
1 \\
1 \\
1\end{array}$ \\
\hline $\begin{array}{l}\text { Diagnosed cases } \\
\text { 'Observation hip' }\end{array}$ & $\begin{array}{l}\cdots \\
\cdots\end{array}$ & $\begin{array}{l}\cdots \\
\cdots\end{array}$ & $\begin{array}{l}\cdots \\
\cdots\end{array}$ & $\begin{array}{l}\cdots \\
\cdots\end{array}$ & $\begin{array}{l}65 \\
33\end{array}$ \\
\hline Total .. & $\ldots$ & .. & . & $\ldots$ & 98 \\
\hline
\end{tabular}

in seven cases and septic arthritis of the hip was found in four. Two cases had previously had osteomyelitis of the upper femur of the same side but no evidence of recurrence of this condition was found on this admission. There was one case each of slipped epiphysis, Still's disease and congenital dislocation of the hip. Various concurrent infections such as otitis media, boils of the leg, paronychia of a finger and $E$. csli urinary infection were also detected.

By rigid exclusion, all cases with traumatic or infective associations have been eliminated and in this way there remains a group of 33 cases of idiopathic hip pain. It is proposed that the diagnosis of 'observation hip' be applied to this group.

\section{Analysis of 33 Cases of 'Observation Hip'}

Sex Ratio. The series is made up of 23 boys and 10 girls. This preponderance of males over females is found in most of the series previously published. This has been explained by the fact that boys are more active and boisterous than girls and are more likely to injure themselves. As has already been

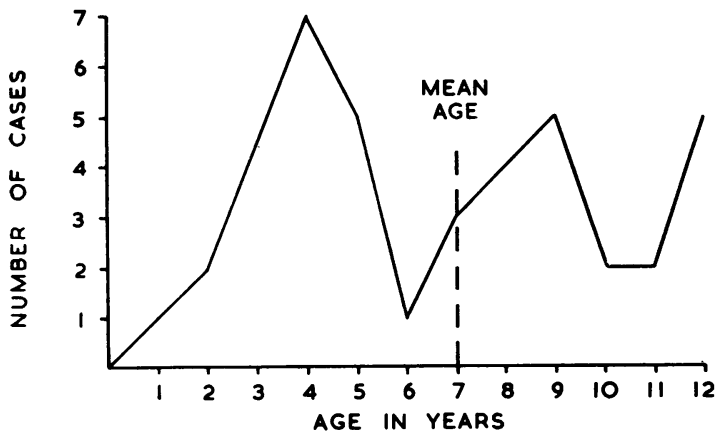

Fig. 1.-Ages of children in the series. stated, no history of injury was recorded in these cases. (It must be remembered that a normal boy will usually deny an injury sustained during some forbidden activity.) Both sides were equally affected, the right hip being painful in 17 and the left in 16 cases.

Age. The ages of the children varied from 1 to 12 years. The number of children in the different age-groups is shown in Fig. 1. The peak between the ages of 4 and 5 years is quite clearly shown.

Fever. A pyrexia of $99^{\circ}$ F. $\left(37 \cdot 2^{\circ}\right.$ C. $)$ was recorded in only seven of the 33 cases and the temperature rapidly settled after the child was put to bed.

Clinical Examination. In all but eight patients, considerable diminution of the range of hip movement was found. This was most marked in internal rotation, external rotation and then abduction being next most affected. A positive Gauvain (1918) sign (spasm of the lower abdominal muscles on sharp internal rotation of the hip) could be elicited whenever hip movements were restricted. Tenderness over the hip was found only once. No other clinical abnormality could be found on examining these children.

Results of Investigations. The W.B.C. and E.S.R. were within normal limits. All throat swabs were clear for pathogenic organisms and radiography of the hips revealed no abnormality.

Treatment. In all patients, pain and spasm settled with no treatment other than complete bed rest, sometimes combined with simple traction for the more exuberant type of child. Analgesics and antibiotics were not required for any of the children in this series.

Duration of Stay. The children were kept in hospital until the pain had gone and there was no limitation of hip movement. The length of time spent in hospital varied from two to 35 days. However, it will be seen from Fig. 2 that most of the cases were discharged within 12 days. Four patients were readmitted with hip pain and were again classified as 'observation hip'. The interval between the first and second admission was six months, one year, two years and three years in each case.

Follow-up. As a routine, every case of 'observation hip' was seen and examined in the clinic within two months of leaving hospital. Of the 


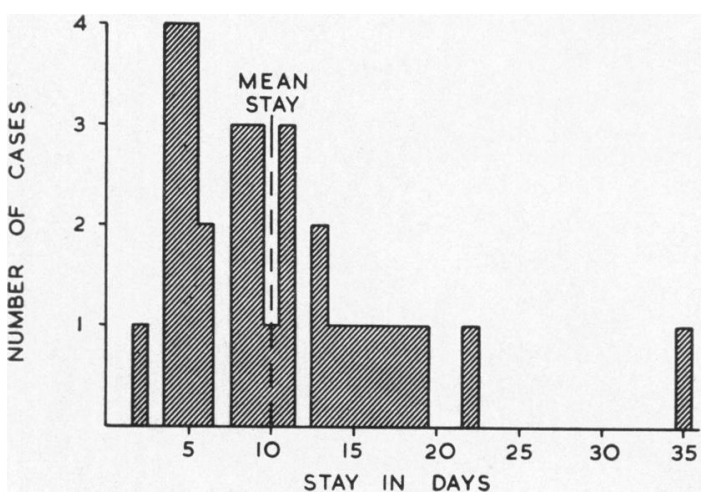

Fig. 2.-Duration of stay in hospital of children in series.

33 cases, 20 were personally interviewed, examined and $x$-rayed. The other 13 patients were examined at least two months after their discharge but further follow-up was not possible. The interval between the original admission and follow-up varied from two months to 10 years; the average follow-up was five years. Thus all were followed up at least two months, and two-thirds were followed up after an average interval of five years.

No abnormality was found on examining the hips of these patients. None of the radiographs showed any evidence of injury, abnormality or disease. After discharge the patients led active lives and complained of no further hip pain.

(One girl who had osteomyelitis of the left lower femoral shaft six years after being admitted with a painful left hip was symptom-free four years after this episode of bone infection.)

\section{Summary and Conclusions}

A historical review of the literature concerning hip pain of unexplained aetiology in children is given. A differential diagnosis of 98 children with hip pain of sudden onset is presented, and after clinical examination and investigation a diagnosis was made in 65 cases, strictly excluding those with infective or traumatic associations. There were thus 33 cases of hip pain where no aetiological factor was present.

An analysis of this series of idiopathic painful hips shows that boys were more frequently affected than girls, the incidence in right and left hips being equal. The children were from 1 to 12 years old, 4 years the commonest age. Most of the patients showed considerable diminution of hip movements, but tenderness of the joint was not a feature. Fever was not found on any occasion.
W.B.C., E.S.R., throat swab and hip radiological examinations were performed in each case and the results of all these investigations were normal. The pain settled completely on no other treatment than rest in bed; simple skin traction was employed on a few patients. Most of the patients were discharged from hospital within a fortnight.

The results of following up this series of patients are also presented. All patients were followed up with an average interval of five years. In no instance was any hip abnormality demonstrated by clinical or radiological examination.

The various papers on this subject suggest traumatic, infective, allergic or toxic theories of aetiology. None of these is applicable to the 33 cases of unexplained hip pain in this series. The terms synovitis, coxitis and arthritis have previously been used with no definite evidence.

It is suggested that the term 'observation hip' be used for these cases, since this does not prejudge the aetiology or pathology and indicates that the patient has had investigations carried out in order to exclude the more serious causes of painful hips in children.

With the knowledge that this condition is not the precursor of any form of hip disease in later life, the clinician is able to explain to the parents of the child affected that the prognosis is most favourable.

I am most grateful to the following: Mr. Lipmann Kessel for his encouragement and advice in the preparation of this paper and for allowing me to study those patients who were under his care; the Medical Records and X-Ray Departments at Fulham Hospital for their help; Mrs. R. Woollerton and Mrs. R. M. Springall for their invaluable secretarial assistance; Mr. M. D. Dixon for the tables and figures.

\section{REFERENCES}

Belmonte, A. C. (1931). Over voorbijaande, goedardige 'Coxitis' (Coxitis Fugax). Ned. T. Geneesk., 75, 197.

Bradford, E. H. (1912). Treatment of hip disease. Amer. J. orthop. Surg., 9, 354

Butler, R. W. (1933). Transitory arthritis of the hip joint in childhood. Brit. med. J., 1, 951.

Caravias, D. E. (1956). The significance of the so-called irritable hips' in children. Arch. Dis. Childh., 31, 415.

Donaldson, W. F. (1955). Transient synovitis of the hip joint. Pediat. Clin. N. Amer., 2, 1073.

Drey, L. (1953). Failure in modeling of bone. Radiology, 61, 645. Edwards, E. G. (1952). Transient synovitis of the hip joint in children report of thirteen cases. J. Amer. med. Ass., 148, 30.

Fairbank, H. A. T. (1926). Discussion on non-tuberculous coxitis in the young. Brit. med. J., 2,828 .

Finder, J. G. (1936). Transient synovitis of the hip joint in childhood. J. Amer. med. Ass., 107, 3.

Fox, K. W. and Griffin, L. L. (1956). Transient synovitis of the hip joint in children. Tex. St. J. Med., 52, 15.

Gauvain, H. J. (1918). Tuberculous disease of hip-joint: A sign of pathological activity. Lancet, $2,666$.

Gianelli, A. and Possenti, B. (1954). Sulla cosidetta sinovite transitoria dell'anca. (So-called transitory synovitis of the hip.) Arch. Ortop. (Milano), 67, 107.

Hermel, M. B. and Sklaroff, D. M. (1954). Roentgen changes in transient synovitis of the hip joint. A.M.A. Arch. Surg., 68, 364 
Jones, J. B. and Ramsay, R. C. (1956). Acute suppurative arthritis of the hip in children. U.S. armed Forces med.J., 7, 1621.

Miller, O. L. (1931). Acute transient epiphysitis of the hip joint. , Amer med

Rauch, S. (1940). Transitory synovitis of the hip joint in children. Amer. J. Dis. Child., 59, 1245.

Rosenberg, N. J. and Smith, E. E. (1956). Transient synovitis of the hip. J. Pediat., 48, 776.
Sterner, G. H. (1954). Flyktig höftledssynovit hos barn. (Transient synovitis of hip in children.) Nord. Med., 51, 203.

Todd, A. H. (1925). The differential diagnosis of non-tuberculous coxitis in children and adolescents. Proc. roy. Soc. Med., 18, Sect. Orthop., p. 31.

Wilson, J. C., Jr. (1955). Childhood limp - diagnosis and treatment. Pediat. Clin. N. Amer., 2, 1021. 